\title{
One of the proposed solutions of the EBM Manifesto Educate the public in evidence-based healthcare to make informed decisions
}

\section{Guylene Theriault}

10.1136/bmjebm-2018-110981

Department of Family Medicine, McGill University, Gatineau, Quebec, Canada

Correspondence to: Dr Guylene Theriault, McGill University Outaouais Medical Campus, Gatineau, QC J8P 7H2, Canada; guylene. theriault@mcgill.ca

\section{Lessons learnt}

Evidence-based healthcare, shared decision making, minimally disruptive medicine and valuebased healthcare are all different tools for shaping the future of healthcare. They represent different ways of addressing various problems many countries are facing in providing more value for patients, improving health and reducing sickness.

As a physician, apart from taking care of patients, I teach the use of evidence in practice, to both students and colleagues. In this text though, I want to relate my experience about something different, that is, educating the lay public.

For many years now, I have had the opportunity to address groups of men and women aged from 30 to 60 years attending preretirement seminars. In that setting, I taught more than 1500 individuals. The themes I cover are diverse but include life habits and their impact on good health, addressing risks, how screening is a choice and questions they should ask their providers when offered different options in addressing their health issues.

I describe some of the lessons I have learnt throughout these years. Some of the conclusions I make have not been formally studied but I share my experience hoping to foster thoughts on how to best address this objective of the EBM manifesto.

\section{First lesson}

Patients are very aware of their responsibility to take control of their life.

It might not seem like it in our offices when we see patients one on one, but every time I conclude a talk, I provide statistics about smoking, poor diet, lack of exercise and the prevalence of diabetes and high blood pressure, and I ask the audience 'Who do you think has the power to change that?'. Every group has the same spontaneous answer: Ourselves. No participant has ever answered: my doctor or the healthcare system.

When addressing these issues with patients, we should probably focus more on motivation than information. ${ }^{1}$

\section{Second lesson}

We need to clearly separate the concepts of prevention and screening.

When I introduce the concepts of prevention and screening, I always make a clear distinction between the two. I find the concepts of primary and secondary prevention to be confusing for nothing. I draw a line and show them that everything we do before the onset of disease is prevention. The period between getting a disease without symptoms and developing symptoms is the period where screening might be possible. This simple, clear distinction makes it easier to answer different types of questions that emerge during the talk. Leaving details out can increase comprehension.

\section{Third lesson}

State upfront that what you are about to say may not make sense at first, as it is counterintuitive.

When I talk about screening, most are surprised by the fact that screening is not always useful. The notion that 'earlier is better' is anchored very deeply. When I then explain the concept of overdiagnosis, I sense confusion among participants. I have found that the best way to address this is to acknowledge, before starting my explanation, how counterintuitive what I am about to say is. And I often repeat this fact when I give more information or when I answer questions.

The analogy with the turtle ${ }^{2}$ to explain overdiagnosis (the turtle is an image for a cancer growing so slowly that it would not cause any problem) and explaining that not all cancer starts with a cell that will multiply and eventually causes death is what seems to work best in explaining this difficult concept.

But really, just stating upfront that these concepts might be counterintuitive has helped me a lot, as it gives attendees the right not to understand and ask questions.

\section{Fourth lesson}

Patients intuitively think about quality of life.

Something always amaze me when I teach groups of patients about screening. I explain the concept of 'lead time bias' by comparing what happens to two individuals. One has been screened and is diagnosed earlier. The other is diagnosed later when he develops symptoms. In the end, both individuals die at the same time. When I ask 'Who has lived the longest' I always get the same answer. And it is not what I had expected. For every group, the man diagnosed later lived the longest. At first, this surprised me as my slide clearly indicates that they died at the same time. Attendees always infer that because the second individual did not know about the 
disease for a longer time, he had a better quality of life, so he 'lived' the longest.

We should never assume we know what our patients think. If we let them talk they will share what is important for them. ${ }^{3}$

\section{Fifth lesson}

We need to be careful about the numbers we use. ${ }^{4}$

I use a hypothetical scenario of a new drug that decreases heart attacks by 50\%. After asking the attendees if they would take the drug, I ask if they have a question for me. When I have used this example with physicians, all groups say "what is the baseline risk?'. But this is not the answer patients give (or rarely). Most groups do not even think of asking that question even when prompted. They have good questions about side effects, cost and alternatives which in comparison rarely comes up with groups of physicians.

Using simple statistics, giving absolute natural numbers helps in understanding the magnitude of risk or benefit. ${ }^{5}$

\section{Sixth lesson}

Patients are ready to have discussions about pros and cons of screening, preventive medication and therapeutic alternatives. ${ }^{6}$

In fact, so many participants are glad to hear that their opinion matters. They understand that medicine and care are not all black and white so I believe we should not be afraid to acknowledge and share uncertainties. I have heard so many times 'Thank you for your honesty, for laying it out like it is', to convince me that patients are ready.

Patients understand that problems can have many solutions. Share the uncertainties with confidence. ${ }^{78}$

\section{Conclusion}

Educating the public in aspects of EBM has potential to improve healthcare sustainability while raising quality of care. ${ }^{9} 10$

This teaching experience has given me an insight into patient's way of thinking that is different from what I could grasp in consultations. These lessons, in addition to being useful in my teaching activities, have opened my mind to practicing differently, and I believe that this is for the benefit of my patients.
Focusing on the patient's goals, making patients partners, acknowledging there are often many ways to approach a problem and positively welcoming questions and doubts from patients has improved my work satisfaction.

I am convinced that patients want to play a role in the decisions about their health, and I believe that patients are ready to truly share decision-making. Sharing decisions has become the best part of my practice. That does not mean though that I have put my knowledge aside. I just use it in a different way.

Competing interests None declared.

Patient consent Not required.

Provenance and peer review Commissioned; internally peer reviewed.

\section{References}

1. Hardcastle SJ, Hancox J, Hattar A, et al. Motivating the unmotivated: how can health behavior be changed in those unwilling to change? Front Psychol 2015;6:835.

2. Welch G. Less Medicine More Health: Book. Beacon press, 2015.

3. King A, Hoppe RB. "Best practice" for patient-centered communication: a narrative review. J Grad Med Educ 2013;5:385-93.

4. Sheridan SL, Pignone MP, Lewis CL. A randomized comparison of patients' understanding of number needed to treat and other common risk reduction formats. J Gen Intern Med 2003;18:884-92.

5. Fagerlin A, Zikmund-Fisher BJ, Ubel PA, et al. Helping patients decide: ten steps to better risk communication. J Natl Cancer Inst 2011;103:1436-43.

6. Richards T, Montori VM, Godlee F, et al. Let the patient revolution begin. BMJ 2013;346:f2614.

7. Alam R, Cheraghi-Sohi S, Panagioti M, et al. Managing diagnostic uncertainty in primary care: a systematic critical review. BMC Fam Pract 2017;18:79.

8. Portnoy DB, Han PK, Ferrer RA, et al. Physicians' attitudes about communicating and managing scientific uncertainty differ by perceived ambiguity aversion of their patients. Health Expect 2013;16.

9. NHS England. Involving people in their own health and care: Statutory guidance for clinical commissioning groups and NHS England, 2017.

10. Gibson A, Boddy K, Maguire K, et al. Exploring the impact of providing evidence-based medicine training to service users. Res Involv Engagem 2015;1:10. 